\title{
An old risk factor for COPD: rest in peace, $15 \%$
}

\author{
Paulo César Rodrigues Pinto Corrêa ${ }^{1,2}$
}

\section{TO THE EDITOR:}

A frequent subject of consideration in textbooks and articles in Pulmonology is the information that only $10-15 \%$ of patients who smoke are likely to develop COPD. ${ }^{(1,2)}$ This information is also mentioned in the first and second COPD consensus guidelines established by the Sociedade Brasileira de Pneumologia e Tisiologia (SBPT, Brazilian Thoracic Association), with the rates being 15\% and $12 \%$, respectively. ${ }^{(3,4)}$ Although there was a review of the epidemiology of COPD in the SBPT consensus document released in 2006, ${ }^{(5)}$ the main epidemiological focus of that review was the important study known as PLATINO-Projeto Latino-Americano de Investigação em Obstrução Pulmonar (Latin American Project for the Investigation of Obstructive Lung Disease); however, it failed to challenge the aforementioned concept.(5) The text itself provided grounds for such a challenge, when it pointed out that the PLATINO study-despite its cross-sectional nature-found that the prevalence of COPD in the $>60$-year age group was $25.7 \%$.(5)

The figure of $15 \%$ gained prominence in the medical literature in 1977, when Fletcher \& Peto published an article in the British Medical Journal, ${ }^{(6)}$ summarizing a book released in the previous year. ${ }^{(7)}$ At least two different points in the publication, the authors state that susceptibility is probably not an all-or-nothing attribute; in fact, there is probably a susceptibility spectrum. ${ }^{(7)}$

Because of the limited length of this communication, it is impossible to provide an in-depth, detailed analysis of the methodological issues of the aforementioned book. In brief, the study conclusions were drawn on the basis of short-term (8-year) follow-up (1961-1969) of 792 patients, of whom at least 17 had a clinical diagnosis of asthma (without continuous treatment). (7) Surveys were conducted in the summer of 1961 , followed by others every six months until the summer of 1969 (except in the winters of 1966 and 1967). The age groups formed in the first survey in 1961 included individuals aged 30-34 years, 35-39 years, and so on, and the oldest age group consisted of individuals aged $55-59$ years. At each survey, $\mathrm{FEV}_{1}$ was measured three times, and this variable was measured in 16 surveys. $^{(7)}$ The mean FEV (in liters) of the sample in the initial survey in 1961 was $3.22 \pm 0.72 \mathrm{~L}$, and $4.3 \%$ of the individuals had an $\mathrm{FEV}_{1}$ $<2.0$ L. $^{(7)}$ FVC was measured twice in seven surveys, after FEV ${ }_{1}$ was measured.(7)

In their book, Fletcher \& Peto showed the decline in FEV $_{1}$ by smoking status (103 nonsmokers, 122 former smokers who had quit smoking before 1962, 387 smokers of up to 15 cigarettes per day, and 180 smokers who smoked more than 15 cigarettes per day on average) in men with and without airflow obstruction by spirometry. (7) The men considered as having airflow obstruction were those with an $\mathrm{FEV}_{1}<2.5 \mathrm{~L}$ (individuals with a height of $1.71 \mathrm{~m}$ ), which corresponds to an $\mathrm{FEV}_{1}$ between $50 \%$ and $80 \%$ of predicted, which is classified by the Global Initiative for Chronic Obstructive Lung Disease (GOLD) criteria as GOLD II (moderate COPD)!. A total of $13 \%$ of the 792 patients showed airflow obstruction: therefore, the famous figure of $15 \%$ is a rounding up from $13 \%$ ! $(7,8)$ Those $13 \%$ represent the smokers who were susceptible enough to become very ill because of reduced pulmonary function.

Therefore, there are at least four methodological issues in the study by Fletcher \& Peto: 1) eligibility criteria, which allowed the inclusion of asthma patients; 2) spirometry criteria for obstruction: as per the current criteria, a greater number of smokers would have been classified as having COPD and would therefore be called susceptible; 3 ) the study follow-up period of only 8 years: the classic $\mathrm{FEV}_{1}$ decline curve is an extrapolation based on a short period of observation, a fact that was acknowledged by the authors themselves; and 4) a bias was introduced in 1968 by the authors, who felt obliged to advise smokers with obstruction and with the steepest slope of the FEV curve to quit smoking. ${ }^{(7)}$

Several cohorts with long-term follow-up ${ }^{(9-11)}$ have estimated the risk of smokers developing COPD by using the simplest and most widely used measure in epidemiology: the incidence rate. The number of smokers who continue to smoke and develop airway obstruction has been increasing in various cohorts because a fraction of the patients followed fail to die from competing risks (e.g., cardiovascular risk) at earlier ages.

The Copenhagen City Heart Study (CCHS) is a prospective, population-based study with a random sample of 19,329 white men and women aged 20-93 years and randomly drawn from the Copenhagen Population Registry, Denmark, on January 1, 1976.(9) As part of the CCHS, 8,045 men and women aged 30-60 years and having normal pulmonary function at baseline were followed for 25 years. ${ }^{(10)}$ Spirometry tests were performed in 1981-1983, 1991-1994, and 2001-2003. Four pulmonary function tests were obtained in 2,022 people; the smoking status of those individuals was determined at the fourth test: 581 were never-smokers; 371 were former smokers, and 1,070 were smokers. Among the smokers, there were 614 continuing smokers. (10) The 25 -year cumulative incidence of COPD was $35.5 \%$ in the continuing smokers, and COPD was classified as 
clinically significant in $24.3 \%$ of those individuals. ${ }^{(10)}$ In contrast, the 25-year cumulative incidence of COPD was only $7.8 \%$ in the never-smokers. ${ }^{(10)}$

The Obstructive Lung Disease in Northern Sweden Studies (Olin) have been collecting cross-sectional and longitudinal data on respiratory diseases, including pulmonary function, in various groups drawn from the general population, at different time points since 1985. The first Olin cohort was recruited in December of 1985 , consisting of 6,610 individuals born in 1919-1920, 1934-1935, and 1949-1950.(11) In 1996, the third survey of that cohort was carried out, and responses were obtained from 5,189 individuals. The objective was to measure the prevalence of COPD, as defined by the GOLD criteria, in the cohort. A random sample of 1,500 individuals were invited to undergo a structured interview and pulmonary function tests in 1996 and 1997, and 1,237 completed spirometry with a satisfactory technique. ${ }^{(11)}$ In $1996-1997$, the prevalence of smoking was $23.6 \%$ in men and $25.6 \%$ in women. Those born in 1919-1920, 1934-1935, and 1949-1950 were 46-47 years old, 61-62 years old, and 76-77 years old, respectively, at the time. The study data show that, in the 76- to 77-year age group, continuing to smoke made $50 \%$ of the individuals develop COPD, as defined by the GOLD criteria. ${ }^{(11)}$ Age and smoking have a multiplicative effect, and the odds ratio for COPD in the individuals who were in the 76- to 77-year age group and smoked was 33.66 (95\% CI: 10.53-107.58). ${ }^{(11)}$

In conclusion, a more careful analysis of the classic book by Fletcher \& Peto ${ }^{(7)}$ and the long-term follow-up of several cohorts allow us to reject the still widely quoted idea that "only $15 \%$ of smokers are susceptible to COPD". We have the responsibility of correctly informing the new generation of pulmonologists and of making it widely known to our patients and the general population that up to $50 \%$ of smokers will develop COPD if they smoke long enough and do not die earlier from competing risks. Rest in peace, $15 \%$ !

\section{REFERENCES}

1. Ouellette DR. The answer is fifteen percent: what Is the question? Chest. 2004;125(1);3-5. http://dx.doi.org/10.1378/chest.125.1.3

2. Ito I, Nagai S, Hoshino Y, Muro S, Hirai T, Tsukino M, et al. Risk and severity of COPD is associated with the group-specific component of serum globulin 1F allele. Chest. 2004;125(1):63-70. http://dx.doi. org/10.1378/chest.125.1.63

3. Sociedade Brasileira de Pneumologia e Tisiologia. I Consenso Brasileiro de Doença Pulmonar Obstrutiva Crônica (DPOC). J Pneumol. 2000;26(Suppl 1):S1-S52.

4. Sociedade Brasileira de Pneumologia e Tisiologia. II Consenso Brasileiro sobre Doença Pulmonar Obstrutiva Crônica - DPOC. J Bras Pneumol. 2004;30(Suppl 5):S1-S42.

5. Sociedade Brasileira de Pneumologia e Tisiologia [homepage on the Internet]. Brasília: Sociedade Brasileira de Pneumologia e Tisiologia; c2008 [updated 2008 Jun 20; cited 2016 Apr 1]. Consenso brasileiro sobre doença pulmonar obstrutiva crônica - DPOC - Sociedade Brasileira de Pneumologia e Tisiologia - SBPT - revisão de alguns aspectos de epidemiologia e tratamento da doença estável - 2006. [Adobe Acrobat document, 24p.] Available from: http://www.sbpt. org.br/downloads/arquivos/Consenso_DPOC_SBPT_2006.pdf

6. Fletcher $\mathrm{C}$, Peto $\mathrm{R}$. The natural history of chronic airflow obstruction $\mathrm{Br}$ Med J. 1977;1(6077):1645-8. http://dx.doi.org/10.1136/ bmj.1.6077.1645

7. Fletcher $\mathrm{C}$, Peto $\mathrm{R}$, Tinker $\mathrm{C}$, Speizer $\mathrm{F}$. The natural history of chronic bronchitis and emphysema. New York: Oxford University Press 1976.

8. Rennard SI, Vestbo J. Natural histories of chronic obstructive pulmonary disease. Proc Am Thorac Soc. 2008;5(9):878-83. http:// dx.doi.org/10.1513/pats.200804-0350C

9. Schnohr P, Jensen G, Lange P, Scharling H, Appleyard M. The Copenhagen City Heart Study. Tables with data from the third examination 1991-1994. Eur Heart J. 2001;3(suppl H):H1-H83.

10. Løkke $A$, Lange $P$, Scharling $H$, Fabricius $P$, Vestbo J. Developing COPD: a 25 year follow up study of the general population. Thorax. 2006;61(11):935-9. http://dx.doi.org/10.1136/thx.2006.062802

11. Lundbäck $B$, Lindberg $A$, Lindström $M$, Rönmark $E$, Jonsson $A C$ Jönsson $E$, et al. Not 15 but $50 \%$ of smokers develop COPD?Report from the Obstructive Lung Disease in Northern Sweden Studies. Respir Med. 2003;97(2):115-22. http://dx.doi.org/10.1053/ rmed.2003.1446 